\title{
Complexidade enunciativa na fala infantil: as hesitações
}

\author{
Lourenço Chacon ${ }^{1}$ \\ Programa de Pós-Graduação em Estudos Linguísticos e Programa de Pós-Graduação em Fonoaudiologia, \\ UNESP, São José do Rio Preto/Marília, SP, Brasil \\ Cristina Gonçalves de Melo ${ }^{2}$ \\ Programa de Pós-Graduação em Estudos Linguísticos, UNESP, São José do Rio Preto, SP, Brasil
}

Resumo: A investigação relatada no presente artigo orientou-se pelo seguinte objetivo: verificar em que medida hesitações sinalizariam diferentes modos de negociação entre o sujeito que enuncia e os outros que se mostram como presentes (embora tidos como "exteriores") na enunciação. Os dados foram extraídos de amostras de fala de crianças entre 5 e 6 anos, coletadas em situação escolar. A análise mostrou que as hesitações remeteram à ação de fatos das condições de produção do discurso - como a representação (i) dos papéis assumidos pelos interlocutores, (ii) da própria situação concreta de produção do discurso, (iii) dos objetos discursivos, bem como (iv) a injunção ao dizer. Remeteram, ainda, às diferentes maneiras pelas quais a complexidade da língua (em termos fonológicos, gramaticais e semânticos) se mostrou como problemática para o sujeito enunciador.

Palavras-chave: Complexidade enunciativa; Enunciação; Fala infantil; Hesitações; Discurso.

Title: Enunciative complexity on children's speech: the hesitations

Abstract: The investigation reported on this paper was oriented by the following objective: to verify to what extent the hesitations would signal to different forms of negotiation between the subject who enunciates and the others that are shown as present (even though taken as "exterior") in the enunciation. The data was extracted from samples of 5 to 6 year-old children's speech, collected in school context. The analyses has shown that the hesitations refer to actions of facts from the discourse production conditions - such as the representation (i) of the roles played by the interlocutors, (ii) of the concrete situation of discourse production itself, (iii) of the discoursive objects, as well as (iv) the injunction of speaking. They also refer to the different ways by which the complexities of language (in phonological, grammatical, semantic terms) are shown as problematic to the enunciator subject.

Keywords: Enunciative complexity; Enunciation; Children's speech; Hesitations; Discourse.

\footnotetext{
${ }^{1}$ Livre-docente em Linguística em Fonoaudiologia, Faculdade de Filosofia e Ciências - UNESP - campus de Marília. Apoio CNPq (Processo 307721/2017-5). Orcid: https://orcid.org/0000-0001-8000-7672. E-mail: lourencochacon@yahoo.com.br.

${ }^{2}$ Doutoranda em Estudos Linguísticos, Instituto de Biociências, Letras e Ciências Exatas - UNESP - campus de São José do Rio Preto. Orcid: https://orcid.org/0000-0001-8496-6985. E-mail: cristinag.melo@yahoo.com.br.
} 


\section{Introdução e justificativas}

O presente artigo resultou de exposição que fizemos no III Colóquio Leituras de Émile Benveniste, que ocorreu em outubro de 2019 na Universidade Federal de Pelotas. Essa exposição se articulou à proposta do primeiro tópico relacionado ao pensamento benvenistiano e desenvolvido no referido Colóquio: Efeitos da teoria da linguagem de Benveniste na proposição de outras teorias da linguagem.

Recoberto por esse tópico temático, a exposição que fizemos e o presente artigo - que se desdobrou dela - tiveram como proposta mostrar como a reflexão benvenisteana sobre a enunciação abre caminhos em direção a se detectarem planos mais complexos desse fenômeno, se visto sob outro olhar teórico-metodológico: o dos estudos discursivos. É o que procuraremos demonstrar a seguir, tendo como objeto de análise o funcionamento enunciativo-discursivo das hesitações.

Trata-se de um dos aspectos que, empiricamente, mais nos tem chamando a atenção na fala infantil. Temos atribuído a grande presença de hesitações nessa fala tanto à ação de fatos da língua (como a integração entre informações fonológicas, sintáticas e semânticas), quanto à ação de fatos discursivos (como a demanda de significação posta pelo interlocutor na produção do dizer da criança). Resultados de nossas investigações podem ser vistos, por exemplo, em Melo e Chacon (2015) ou em Chacon e Villega (2015).

Esses resultados despertaram nossa curiosidade quanto a investigar relações entre as hesitações - fenômeno tomado como (mais uma forma de) heterogeneidade mostrada, numa tentativa de expansão das reflexões de Authier-Revuz (1990) - e a heterogeneidade constitutiva do discurso/do sujeito na fala infantil, tal como ela se mostra representada no fio do discurso. Em outras palavras (e já antecipando nosso ponto de vista), no presente artigo, as hesitações serão tomadas como "[...] formas linguísticas de representação de diferentes modos de negociação do sujeito falante com a heterogeneidade constitutiva do seu discurso." (AUTHIER-REVUZ, 1990, p. 26). Para melhor situarmos essa expansão de reflexão ${ }^{3}$, exporemos brevemente características desses dois tipos de heterogeneidades, conforme postulados por essa autora.

O discurso é constitutivamente heterogêneo já que produto de uma rede interdiscursiva. Como se sabe, essa visão da autora assenta-se tanto em contribuições de Pêcheux, quanto em - dentre outras - contribuições do dialogismo do círculo de Bakhtin, sobretudo a de que "[...] as palavras são, sempre e inevitavelmente, as palavras dos outros." (AUTHIER-REVUZ, 1990, p. 26). Além do discurso, também o sujeito é heterogêneo, já que "[...] deslocado, desalojado, em um lugar múltiplo, fundamentalmente heterônimo, [...] a exterioridade está no interior do sujeito" (AUTHIER-REVUZ, 1990, p. 29). Distanciando-se, desse modo, da noção de sujeito como fonte do dizer, com o apoio em preceitos da psicanálise de Freud e em sua releitura por Lacan, Authier-Revuz (1990) propõe que haveria uma ilusão

\footnotetext{
${ }^{3}$ Trata-se de uma expansão na medida em que, até onde temos notícia, nem as hesitações, nem a fala infantil foram objeto específico de investigação e de reflexão por parte de Authier-Revuz.
} 
necessária do eu que sustentaria a imagem de um sujeito autônomo. Com base em Pêcheux, a autora entende que, na produção do discurso, o interdiscurso é ignorado pelo sujeito, o qual, "[...] na ilusão [do eu], se crê fonte deste seu discurso, quando ele nada mais é do que o suporte e o efeito" (AUTHIER-REVUZ, 1990, p. 27).

Essa dupla determinação (do discurso e do sujeito) ocorreria porque, "[...] constitutivamente, no sujeito e no seu discurso está o Outro ${ }^{4 \prime}$, onde se reencontram "[...] as concepções do discurso, da ideologia, e do inconsciente, que as teorias da enunciação não podem, sem riscos para a linguística, esquecer." (AUTHIER-REVUZ, 1990, p. 27 - destaque da autora).

Voltemos às hesitações. O ganho de incluí-las como forma de heterogeneidade mostrada é o de melhor compreendermos a instabilidade enunciativo-discursiva da fala infantil. Acreditamos que tal inclusão seja interessante para a compreensão do processo convencionalmente chamado de aquisição de linguagem, na medida em que, como veremos mais adiante, além de as hesitações comumente não ocuparem o primeiro plano de análise dos fatos da fala infantil, frequentemente são vistas como sinais de um problema (atipia ou sinal de gagueira) de linguagem ${ }^{5}$; não sendo, portanto, em nenhuma dessas duas situações, tomadas, conforme o faremos com base em Authier-Revuz, como um modo de negociação do sujeito falante com a heterogeneidade constitutiva do (seu) discurso.

Assim, entender as hesitações como forma(s) de heterogeneidade mostrada é vê-las como momentos nos quais, no fio do discurso, irrompe a presença discursivamente motivada do outro.

Nessas irrupções, as hesitações indicariam momentos em que o sujeito enunciador tenta se proteger da "ameaça" do outro, tentando contê-la, mas sem sucesso, já que as irrupções deixam, pelo menos, marcas linguísticas de sua ocorrência: pausas silenciosas, pausas preenchidas, alongamentos hesitativos, cortes bruscos e repetições hesitativas. A exemplo de outras marcas de heterogeneidade mostrada, é a presença do outro que, nesses momentos, "[...] insiste em quebrar a continuidade, a homogeneidade fazendo vacilar o domínio do sujeito [...]" (AUTHIER-REVUZ, 1990, p. 33), ocasionando essas irrupções.

Vale salientar, conforme antecipamos, que características discursivas diretamente relacionadas com hesitações foram muito pouco destacadas nos trabalhos que investigam a fala infantil. Embora a hesitação seja tematizada nesses trabalhos, ela o é preferencialmente fora do escopo enunciativo-discursivo. É o que procuraremos mostrar ao expormos as diferentes maneiras pelas quais sua presença é descrita na literatura.

\footnotetext{
${ }^{4}$ Embora não defina o estatuto da diferença, Authier-Revuz (1990) distingue, em sua proposta, o "Outro" e o "outro". O "Outro" corresponderia ao que a autora chama de "alteridade radical", aquela que provém das determinações ideológicas do sujeito/do discurso, bem como de suas determinações inconscientes. Já o "outro" corresponderia à alteridade que é mostrada no fio do discurso e tida como "exterior" (AUTHIER-REVUZ, 1990, p. 30) ao discurso do sujeito enunciador.

${ }^{5}$ Sobretudo no campo da Fonoaudiologia. Conforme antecipamos, mais à frente descreveremos como as hesitações são preferencialmente vistas nesse campo.
} 
Identificamos quatro tendências recorrentes de abordagem das hesitações, a saber, vê-las como relacionadas: à fluência/disfluência de fala (Seção 1.1); à prosódia (Seção 1.2); aos vínculos entre subjetividade e gagueira (Seção 1.3); e à subjetividade, porém fora do contexto da patologia (Seção 1.4). Após expormos características dessas quatro tendências, faremos uma análise global delas (Seção 1.5).

\section{Hesitação relacionada à fluência/disfluência}

Em 1999, a American Speech-Language-Hearing Association (ASHA) postulou uma declaração oficial sobre os distúrbios da fluência, uma vez que esses distúrbios apresentariam problemas terminológicos, dificultando a pesquisa, os processos terapêuticos e os diagnósticos. Para a definição do termo "fluência" foram destacadas: (1) características do que ela NÃO seria, já que esse termo remete à "[...] fala que não contém desvios perceptíveis na suavidade ou [em seu] fluxo." (ASHA, 1999, p. 3); bem como (2) características diferenciais em relação àquelas recobertas pelo termo "gagueira", já que a fluência remeteria a sequências de fala livres de rupturas. Nesse contexto, a fluência é, então, definida como “[...] aspecto da produção da fala que se refere à continuidade, suavidade, velocidade e/ou esforço com o qual unidades fonológicas, lexicais, morfológicas e/ou sintáticas da língua são faladas" (ASHA, 1999, p. 3). Já o termo que remete à contraparte de "fluência", ou seja, "disfluência", refere-se a "[...] quebras na continuidade da produção de unidades da língua - fonológicas, lexicais, morfológicas e/ou sintáticas - em sua modalidade oral." (ASHA, 1999, p. 4). A ASHA esclarece que a disfluência não implica necessariamente em anormalidade e que foi erroneamente confundida com a gagueira. Destaca, por fim, que as disfluências normais do desenvolvimento podem ocorrer em crianças pré-escolares em período normal de aquisição de linguagem.

Em estudos que se desenvolvem sob tal perspectiva - como Watson e Anderson (2001), Carlo e Watson (2003), Juste e Andrade (2006), Natke et al. 2006), Boeya et al. (2007), Martins e Andrade (2008) -, as hesitações são relacionadas a condições consideradas atípicas (como a gagueira), ou figuram em comparações entre o que é tido como típico e o que é tido como atípico na fala infantil. Nesses estudos, as hesitações figuram (dentre outros) como um tipo de disfluência. Destaque-se, ainda, que vários outros fenômenos linguísticos que, nesses estudos, são tidos como tipos de disfluência correspondem a fenômenos que, na literatura linguística sobre as hesitações, constituiriam algumas de suas marcas características - como repetições, truncamentos (ou interrupções) e alongamentos (ou prolongamentos).

Em outras palavras, a principal preocupação desses trabalhos é caracterizar a fala tida como típica e a fala tida como atípica, tendo como critério principal a investigação das relações entre momentos fluentes e momentos disfluentes desses dois tipos de fala - dentre os quais se incluem aqueles que, na literatura linguística, se explicam como momentos de hesitações.

Vejamos o que ocorre com os trabalhos que incluímos no segundo grupo. 


\section{Hesitação relacionada à prosódia}

Os trabalhos que incluímos nesse grupo buscam identificar domínios prosódicos que melhor explicariam a distribuição das hesitações na fala (especialmente na fala infantil).

Nesses trabalhos, trechos fluentes revelariam partes já congeladas que coincidiriam com o acento frasal ou núcleo do grupo entonacional. As hesitações (dentre outros tipos de disfluências) não ocorreriam nesses pontos prosódicos, mas naqueles periféricos e fronteiriços que os circundam (SCARPA, 1995). Desse modo, embora discursivamente imprevisíveis, não seriam prosodicamente aleatórias (SCARPA, 2015).

Também nesse grupo, a distribuição dos pontos de hesitação seria "[...] um importante recurso linguístico de observação dos domínios prosódicos que se mostram como mais, ou menos, dominados pelas crianças na aquisição da linguagem." (MELO; CHACON, 2015, p. 18).

Como se pode verificar, nesse segundo grupo de trabalhos, a preocupação é com as determinações prosódicas das disfluências, marcadas por hesitações, sem a preocupação de distinguir a fala típica da fala atípica na criança.

Vejamos o que propõem os trabalhos que classificamos como do terceiro grupo.

\section{Hesitação na relação entre subjetividade e patologia}

Nesse terceiro grupo, as hesitações se mostram como indícios das relações entre subjetividade e patologia, no contexto da gagueira. Trata-se de estudos baseados, fundamentalmente, em de Lemos (2002), a partir da releitura que essa autora faz dos processos metafóricos e metonímicos postulados por Jakobson (1963[1995]).

Façamos aqui um parêntese. Embora, em seus trabalhos, de Lemos não tenha feito análises específicas sobre as hesitações, são dignas de destaque suas considerações sobre elas, especialmente em razão da valiosíssima contribuição de seus estudos para a compreensão da fala infantil. Antes de descrevermos as características que destacaremos dos trabalhos que incluímos em nosso terceiro grupo e que, como dissemos, se ancoram em de Lemos (2002), vejamos em que contexto as hesitações são mencionadas nesse seu trabalho a saber, quando essa autora discute a dominância da relação do sujeito com sua própria fala.

Segundo a autora, nesse movimento, a criança "[...] se dividiria entre aquele que fala e aquele que escuta sua própria fala, sendo capaz de retomá-la, reformulá-la e reconhecer a diferença entre sua fala e a fala do outro" (DE LEMOS, 2002, p. 56). Trata-se de um movimento no qual a emergência de hesitações (dentre outros recursos linguísticos) mostraria o efeito da própria língua e da fala do adulto sobre o sujeito (DE LEMOS, 2002). Portanto, hesitações poderiam ser vistas, de acordo com de Lemos (2002), como indícios de mudança de posição do sujeito em relação à fala do adulto e à língua. Nessa mudança, elas mostrariam, então, (i) seu distanciamento em relação a essa fala adulta e (ii) o efeito da escuta de sua própria fala pela criança. Como se vê, a autora destaca a transformação de processos intersubjetivos em 
processos intra-subjetivos, ou em suas palavras, “[...] a trajetória da criança de infans a sujeito falante" (DE LEMOS, 2002, p. 56).

Fazemos esse destaque a de Lemos (2002) uma vez que, embora esta não seja a concepção que sustenta nossa abordagem das hesitações, ela pode contribuir para sustentar a proposta de que as hesitações constituem formas de heterogeneidade mostrada, na medida em que remetem à emergência do sujeito na cadeia significante, sujeito que, conforme depreendemos a partir da leitura de de Lemos (2002) e de Authier-Revuz (1990), é constitutivamente heterogêneo (dividido).

Encerramos aqui o parêntese. Voltemos, então, às principais conclusões dos trabalhos do terceiro grupo. Uma delas é a de que a gagueira infantil se manifesta quando "[...] a criança revela estar à escuta da própria fala" (CARNEIRO, 2006, p. 450). Nessa escuta, em decorrência da prisão da criança em uma sobreposição dos eixos (sintagmático e paradigmático) da linguagem, a tensão se manifestaria no corpo que fala ou que ouve, e o sentido ficaria suspenso. Desse modo, diante de cada manifestação de fala gaga, se estaria não só diante do acometimento de uma gagueira mas, sobretudo, de um sujeito sob efeito da escuta de sua própria fala.

Outra importante conclusão é a de que seria preciso compreender a disfluência como constitutiva da relação sujeito/linguagem. Mudar-se-ia, pois, a visão do sujeito gago, desta feita como um "[...] sujeito-falante fluente, não marginalizado, não discriminado, considerando a fluência como relativa, uma vez que não há fluência linear, pois todos nós somos disfluentes." (AZEVEDO; LUCENA, 2009, p. 184).

Nesse terceiro grupo de trabalhos, como se vê, apesar de as hesitações figurarem no contexto da patologia - já que o foco dos trabalhos é a gagueira -, elas servem como elementos de desconstrução da patologia, pelo viés das relações entre subjetividade e gagueira. É o que distingue, a nosso ver, esse terceiro grupo de trabalhos daqueles cujas características expusemos no primeiro grupo - em que não se problematizava, mas se reafirmava, a distinção entre normalidade e patologia (por meio da descrição de disfluências como as hesitações - dentre outras).

A seguir, exporemos características dos trabalhos que incluímos no que classificamos como quarto grupo.

Hesitação como indício de subjetividade fora do contexto da patologia

Nessa quarta tendência, encontramos trabalhos em que a hesitação também é analisada como marca/indício de subjetividade, mas sem que a discussão a seu respeito sirva para distinguir normalidade e patologia, ou para problematizar a patologia.

Nesse grupo, uma das visões é a de que disfluências como as hesitações seriam importantes para a compreensão do funcionamento da linguagem, já que se constituiriam como "[...] pontos em que o sujeito se revela [...]" (RAMOS; SCARPA, 2007, p. 354), ou, ainda, como evidências da emergência do sujeito (RAMOS, 2008) na linguagem. 
Ainda nesse grupo a subjetividade se mostraria, por meio das hesitações, em pontos que indicariam (também) a instabilidade da própria língua. Ou seja, as hesitações mostrariam momentos de conflito da relação do sujeito com a complexidade da língua (CHACON; VILLEGA, 2012).

Como se pode verificar, nesse quarto grupo de trabalhos, as hesitações, vistas no contexto das disfluências, são tidas como inerentes à fala e como marcas da relação do sujeito com a linguagem.

\section{Análise da literatura encontrada}

Uma análise global desses quatro diferentes grupos de trabalhos permite, a nosso ver, identificar duas grandes divisões em seu interior.

No que se refere à primeira grande divisão, é bastante forte a relação entre hesitações e condições tidas como de exceção (ou marcadas) da linguagem - como a disfluência e a patologia. Em outras palavras, como já alertava Scarpa (1995), predomina, nesses trabalhos, uma visão negativa dos fatos envolvidos nas chamadas disfluências - como, dentre outros, as hesitações. Mesmo os trabalhos que, em nossa exposição, se distanciam dessa visão, forçosamente a têm como um outro com o qual, necessariamente, há que se negociar/dialogar.

Ainda na primeira grande divisão, a mesma literatura pode ser vista conforme a seguinte repartição: (i) trabalhos - descritos em 1.1 - que olham para as hesitações como fatos desvinculados da linguagem e (ii) trabalhos - descritos em 1.2, 1.3 e 1.4 - que olham para elas como fatos da própria linguagem. Ou seja, em (i), os autores as concebem como motivadas por aspectos não linguísticos do indivíduo ao produzir a fala - como aqueles que, na interação entre aspectos orgânicos e não-orgânicos do indivíduo, produziriam a (sua) gagueira -, enquanto que, em (ii), os autores as veem como decorrentes do funcionamento da linguagem.

Em nossa abordagem das hesitações, distanciamo-nos da visão que analisa as hesitações encerrando-as em si mesmas ou relacionando-as exclusivamente a aspectos internos (orgânicos e não-orgânicos) do indivíduo. Como as vemos como formas de heterogeneidade mostrada, aproximamo-nos, portanto, da visão que as vê como fatos de linguagem que se mostram nas produções verbais dos sujeitos.

No que se refere à segunda grande divisão, a análise global dos diferentes grupos de trabalhos comentados permite, também, identificar outra repartição: (iii) trabalhos como os descritos em 1.1, que se calcam numa visão de sujeito livre e provido de intenção, colocado, portanto, como o centro do processo do dizer; e (iv) trabalhos como os descritos em 1.2, 1.3 e 1.4, nos quais já se observam indícios de distanciamento dessa identificação do sujeito com o eu que se vê como fonte do dizer.

Vamos nos distanciar da visão que vê o sujeito como centro do processo, e nos aproximar da visão que descentra o sujeito. Seguindo Authier-Revuz, questionamos esse tipo 
de visão do sujeito enunciador ${ }^{6}$ pelo fato de que ele é colocado "[...] como fonte autônoma do sentido que comunica através da língua." (AUTHIER-REVUZ, 1990, p. 26). Na visão da autora, que compartilhamos, apoiada em Freud: "[...] não há centro para o sujeito fora da ilusão e do fantasmagórico, mas que é função desta instância do sujeito que é o eu ser portadora desta ilusão necessária." (AUTHIER-REVUZ, 1990, p. 28 - destaques da autora).

Distanciamo-nos, portanto, da ideia de centralidade do sujeito, por entendermos, com Authier-Revuz (1990), que, na ilusão necessária do eu que enuncia como centro do processo enunciativo, é possível a recuperação de negociações do sujeito enunciador com os outros constitutivos da produção do discurso. Isso porque, durante a produção do discurso, o interdiscurso é ignorado pelo sujeito, que, "[...] na ilusão, se crê fonte deste seu discurso, quando ele nada mais é do que o suporte e o efeito" (AUTHIER-REVUZ, 1990, p. 27).

Como pretendemos investigar, conforme antecipamos, relações entre a hesitação como forma de heterogeneidade mostrada e aspectos constitutivos do discurso representados na fala infantil, procuramos testar a hipótese de que conflitos gerados pela rede interdiscursiva da fala infantil, e mostrados por meio de hesitações, não se pautariam pela aleatoriedade, mas se explicariam em função da constituição dessa própria rede interdiscursiva.

Para tanto, estabelecida a hipótese de pesquisa, pretende-se testá-la na busca de respostas à seguinte questão: dado que esses conflitos não são aleatórios, e dada a materialidade da língua no discurso, em que medida a presença de hesitações, além de remeter à ordem do discurso, não remeteria, também, à ordem da língua?

A fim de responder a essa pergunta de pesquisa, a presente investigação será orientada pelo seguinte objetivo:

(1) verificar em que medida hesitações se constituiriam em diferentes modos de negociação entre o sujeito que enuncia e os outros que se mostram como presentes (embora tidos como "exteriores") na enunciação.

A presente investigação pretende contribuir para uma melhor compreensão do funcionamento das hesitações (e mesmo da fluência) pela análise de como, ao falarem, as crianças, enquanto sujeitos, se inscrevem no discurso, pelas formas de heterogeneidade mostrada. São, também, esperadas contribuições para o entendimento das formulações e reformulações constitutivas da fala infantil, possibilitando, assim, incrementar o conhecimento teórico sobre a compreensão das instabilidades nessa fala.

\section{Materiais e métodos}

Tipo de estudo

\footnotetext{
${ }^{6}$ A crítica a essa visão sobre o sujeito enunciador é, no entanto, acompanhada de uma proposta por parte da autora: "Assim, a atenção às formas concretas da representação da enunciação que são, entre outras, as formas da heterogeneidade mostrada, pode contribuir, no âmbito do discurso, para manter a distinção entre o eu pleno e o sujeito que, ele, atropela [...] para recolocar tal distinção no nível dos mecanismos produtores dessa ilusão." (AUTHIER-REVUZ, 1990, p. 36).
} 
Trata-se de uma análise qualitativa, com ênfase em características discursivas da fala infantil.

Banco de dados

Para a realização deste estudo, utilizamos material coletado em 2011, proveniente do Banco de Dados Apropriação do Conhecimento na Linguagem Infantil (ACoLI), composto por dados de natureza semicontrolada de conversação entre 24 crianças e duas documentadoras (identificadas, na análise que se seguirá, pelas siglas DJZ e DTM). Esse tipo de situação de coleta, não distante de situações reais de conversação, acabou por favorecer a emergência de formas de heterogeneidade mostrada (como a que investigamos) nas produções das crianças.

Como critérios de inclusão das crianças para a constituição do banco de dados, foram considerados um critério relacionado à saúde da criança e outro relacionado à configuração ética da própria pesquisa: (a) a ausência, nesses sujeitos, de problemas de linguagem condição referendada por procedimentos de avaliação fonoaudiológica de linguagem, bem como de triagem auditiva, sendo excluídas da amostra (e encaminhadas para avaliação) aquelas crianças que apresentaram, em relação a esses aspectos, algum padrão desviante; e (b) a assinatura, pelos responsáveis, de um Termo de Consentimento Livre e Esclarecido que autorizava a participação das crianças na pesquisa. No total, das 24 crianças registradas, 16 são do sexo masculino e 8 do sexo feminino.

\section{Corpus}

Foi necessário lançar mão de um recorte para que a análise pudesse detectar as principais características enunciativo-discursivas do grupo analisado. Por esse motivo, selecionamos gravações de quatro sessões de entrevistas semidirigidas com três crianças do sexo masculino (identificadas, na análise que se seguirá, como SEC, SLE e SVV) entre 5-6 anos - o que totaliza um corpus previsto de 12 amostras ( 3 crianças $X 4$ sessões).

Como critérios de inclusão para a seleção das quatro sessões de entrevistas, levamos em conta o fato de: (a) duas propostas corresponderem a recontagens de histórias lidas para as crianças em sala de aula; e (b) duas propostas corresponderem ao relato de duas experiências que as crianças vivenciaram fora de sala de aula. Já como critério de seleção dessas três crianças, foi considerada sua presença a 100\% das gravações.

\section{Forma de análise dos resultados}

A forma de análise dos resultados será descrita de acordo com o objetivo proposto para a pesquisa. 
Relembremos que, segundo nossa visão das hesitações, elas mostram momentos em que o sujeito que enuncia tenta se proteger da "ameaça" do outro, tentando contê-la. Essas tentativas de contenção, no entanto, deixam traços no fio do discurso, sob a forma de marcas linguísticas como pausas silenciosas, pausas preenchidas, alongamentos hesitativos, cortes bruscos e repetições hesitativas. Para a descrição formal das hesitações, ou seja, para identificarmos as marcas linguísticas com que elas irrompem na cadeia discursiva, baseamonos em Marcuschi (1999 e 2006) e em complementações/ajustes de sua proposta feitas por Nascimento (2005), Chacon e Camilo (2014) e Vieira e Chacon (2015). Optamos por essa classificação já que ela se baseia numa visão das hesitações como fenômenos que emergem "[...] em contextos interativos de natureza oral e não [como] uma disfunção do falante." (MARCUSCHI, 1999, p. 159). Ainda para esse autor, as hesitações podem ter motivações discursivas, preservando a fluência, já que a fala, mesmo com hesitações, pode continuar fluente (MARCUSCHI, 1999, p. 163). Em outras palavras, na visão defendida por Marcuschi, além de as hesitações não se configurarem como marcas de disfluência, elas podem resultar de fatos discursivos (embora sejam diferentes as concepções de discurso assumidas por Marcuschi e por nós) ${ }^{7}$.

Desse modo, para analisar os resultados referentes ao objetivo da pesquisa - verificar em que medida hesitações se constituiriam em diferentes modos de negociação entre o sujeito que enuncia e os outros que se mostram como presentes (embora tidos como "exteriores") na enunciação -, buscamos quais elementos dessa heterogeneidade afetariam mais fortemente a produção do discurso nos momentos em que emergem as hesitações. Trata-se de elementos que, conforme detectamos em inspeções feitas nos dados, apontam tanto para fatos das condições de produção do discurso, quanto para a ação da própria língua nessa produção. No primeiro caso, esses elementos remetem, por exemplo, à representação dos lugares/papéis assumidos pelos interlocutores, à representação da própria situação concreta de produção do discurso, à representação dos objetos discursivos, à injunção ao dizer, dentre outros. No segundo caso, remetem às diferentes maneiras pelas quais a complexidade da língua (em termos fonológicos, gramaticais e semânticos) se mostra como problemática para o sujeito enunciador.

\section{Análise}

Iniciaremos a presente seção relembrando que, para nós, hesitações correspondem a momentos nos quais, no fio do discurso, irrompe a presença do outro. Relembremos também que irrupções deixam marcas linguísticas de sua ocorrência - que quebram "[...] a continuidade, a homogeneidade fazendo vacilar o domínio do sujeito [...]" (AUTHIER-REVUZ, 1990, p. 33), ocasionando essas irrupções.

\footnotetext{
${ }^{7}$ Nosso distanciamento se deve ao fato de a concepção (não explicitada) de discurso em Marcuschi estar fortemente relacionada à ideia de produção do texto falado, orientada por processos, ao mesmo tempo, interacionais, cognitivos e textuais.
} 
É o que se pode verificar, por exemplo, na Ocorrência 01:

\author{
Ocorrência 01 \\ SLE olha + a a lebre ficou zombando da tartaruga + e ela correu bem rápido + a \\ tartaruga tava com chapéu e com cabelo \\ DJZ ah ela tinha chapéu e cabelo? \\ SLE óculos + ó + tam + também:: + bolsa + e é/ e ela + e a + e a lebre era bem teimosa
}

Dois momentos hesitativos emergem no enunciado destacado em itálico, em que são descritas características da personagem de uma narrativa (a tartaruga - em A lebre e a tartaruga).

O primeiro momento hesitativo (+ tam + também:: + bolsa) é mostrado linguisticamente por meio de uma marca combinada de hesitação composta de pausa silenciosa, gaguejamento, alongamento e nova pausa silenciosa antes da palavra "bolsa". Um primeiro conflito (de natureza semântica) que se mostra aí seria o da concorrência entre vários objetos passíveis de serem enumerados e com os quais a personagem (pela visão do eu) é caracterizada na história. Mas detecta-se ainda aí um segundo conflito (de natureza fonológica), aquele entre o fechamento prosódico da primeira parte de um enunciado fonológico - a frase entonacional reestruturada (NESPOR; VOGEL, 1986) oh também bolsa - e a abertura da segunda parte do mesmo enunciado fonológico (NESPOR; VOGEL, 1986) - da qual consta a frase entonacional e a lebre era bem teimosa. Desse modo, um fato das condições discursivas de produção desse enunciado (a resposta ao interlocutor sobre características de uma personagem) e um fato da língua (a relação entre dois constituintes prosódicos) se mostram, pois, por essa marca hesitativa complexa.

Situação semelhante se verifica no segundo momento hesitativo (e é/ e ela + e a + e a lebre era bem teimosa). Mantendo-se as mesmas condições discursivas de produção, a segunda parte do enunciado fonológico se inicia com uma marca combinada de hesitação, composta por gaguejamento, corte brusco, pausa silenciosa e repetição hesitativa. Detectase nessa marca um conflito que mostra uma possível concorrência entre "ela" e "a lebre". Mas, longe de se caracterizar pela competição, no fio do discurso, entre um nome e seu pronome pessoal correspondente, essa marca combinada de hesitação parece apontar para dois momentos de escuta (por parte do eu) de sua própria fala: o primeiro, da não coincidência entre "ela" e "ela", no sentido de que "ela" recobriria tanto a personagem "lebre", quanto a personagem "tartaruga". Daí, talvez, um segundo momento de escuta, mostrado pela parte da hesitação que corresponde à repetição hesitativa (e $a+e$ a), em que emerge no fio do discurso "lebre", como a contraparte negada de "tartaruga" - ou, ainda, como uma volta ao tópico apresentado no primeiro enunciado de SLE: lebre, em olha + a a lebre ficou zombando da tartaruga.

Mas observa-se, ainda nessa marca, outro conflito, aquele do início da emergência, no fio do discurso, de mais uma frase entonacional: e a lebre era bem teimosa. Recorde-se que, como já observado por Scarpa (1995), fato que aqui confirmamos, o momento hesitativo incide sobre porções prosodicamente fracas dessa frase entonacional, a saber, sobre os 
clíticos "e" e "a". Fato ainda a ser destacado a esse respeito é o de que a frase entonacional, em sua constituição, integra informações prosódicas, sintáticas e semânticas (NESPOR; VOGEL, 1986). Diferentemente das duas frases entonacionais que a precedem - (i) óculos e (ii) oh também bolsa - na terceira, além de outra organização sintática, se verifica um deslocamento semântico. Com efeito, enquanto nas duas primeiras a informação semântica associada à informação prosódica dizia respeito a características "exteriores" da personagem tartaruga (ter óculos e ter bolsa), na terceira, o sentido desliza para uma característica "interior" da personagem lebre (a de ser bem teimosa).

Portanto, mais uma vez, o segundo momento de hesitação do enunciado, ao mesmo tempo, mostra conflitos que parecem decorrer tanto da ordem do discurso quanto da ordem da língua.

Mas em que medida conflitos mostrados pelas hesitações mostrariam a complexidade enunciativa?

Uma resposta inicial parece ser aquela contida na descrição do possível conflito entre "ela", "a lebre" e "a tartaruga". Quando o descrevemos, o interpretamos como indícios de escutas do eu sobre sua própria fala. Se essa interpretação se mostra como razoável é porque esse eu, sujeito da enunciação, seria, em sua constituição, clivado, dividido. É essa divisão/dispersão constitutiva que permitirá, então, que a figura enunciativa mostrada, no fio do discurso, como o eu que enuncia mostre a quebra da ilusão de sua unidade ao "escutar" de diferentes lugares sua própria fala. Temos, assim, nessa interpretação, um primeiro indício da complexidade enunciativa dessa fala.

No entanto, essa complexidade pode ser constatada mais nitidamente se recuperarmos características - hoje clássicas - da enunciação em Benveniste (1989):

\footnotetext{
Enquanto realização individual, a enunciação pode se definir, em relação à língua, como um processo de apropriação. O locutor se apropria do aparelho formal da língua e enuncia sua posição de locutor por meio de índices específicos, de um lado, e por meio de procedimentos acessórios, de outro.

Mas imediatamente, desde que ele se declara locutor e assume a língua, ele implanta o outro diante de si, qualquer que seja o grau de presença que ele atribua a este outro. Toda enunciação é, explícita ou implicitamente, uma alocução, ela postula um alocutário.

Por fim, na enunciação, a língua se acha empregada para a expressão de uma certa relação com o mundo. A condição mesma dessa mobilização e dessa apropriação da língua é, para o locutor, a necessidade de referir pelo discurso e, para o outro, a possibilidade de co-referir identicamente, no consenso pragmático que faz de cada locutor um co-locutor. A referência é parte integrante da enunciação (BENVENISTE, 1989, p. 84 - destaques do autor).
}

Vamos associar esse conjunto de características à seguinte cena enunciativa:

Ocorrência 02

DJZ e pra que que a gente coloca o fermento no bolo?

SVV pra ++ num sei o que falar

DJZ você num sabe o que falar?

SVV não 
DJZ ó + a gente coloca

SVV acho que o professor L. não vai gostar

DJZ ah ((risos)) vai sim V. ó é só você pensar um pouquinho vamos lá + a gente colocou o quê? as meninas colocaram o que no bolo 'cê lembra?

Dessa ocorrência, vamos nos deter no primeiro enunciado de SVV (pra ++ num sei o que falar). Na alocução que o caracteriza, a relação eu-tu se constrói, empiricamente, entre a criança SVV (que se introduz como locutor em sua fala por meio da marca de primeira pessoa do presente do verbo "saber") e postula como alocutário a documentadora DJZ (mas sem que a presença de marcas dessa posição sejam introduzidas em sua fala).

Nesse enunciado, um conflito irrompe em seu fio, mostrado pela marca hesitativa pausa silenciosa (com duração média). Essa marca emerge justamente no momento em que a referência seria apresentada no enunciado - como se pode depreender da expressão "o que" na sequência "num sei o que falar". Mas por que a referência é silenciada, ou, em outras palavras, por que justamente o que dizer é silenciado?

Para responder a essa questão, além da hipótese mais imediata de que a criança desconhecia a utilidade do fermento, é necessário retomarmos fatos das condições de produção não apenas desse, mas de todos os enunciados que compõem nossa amostra. Esses enunciados foram produzidos como parte de uma atividade pedagógica complexa. Era de conhecimento de todos os envolvidos (equipe pedagógica da escola, crianças, coordenador do projeto e documentadoras) que a atividade visava verificar em que medida conteúdos trabalhados nela chegavam às crianças. Embora diretamente não tenha sido dito às crianças que elas seriam avaliadas quanto a esse aspecto, o próprio fato de serem mensalmente interrogadas sobre conteúdos de atividades das quais participaram Ihes permitia identificar um teste de conhecimento - ou seja, de que, de algum modo, estavam sendo avaliadas. É o que se depreende, por exemplo, do deslocamento semântico que se verifica no último enunciado de SEC na ocorrência a seguir, não alinhado sintática e semanticamente aos enunciados que o precedem:

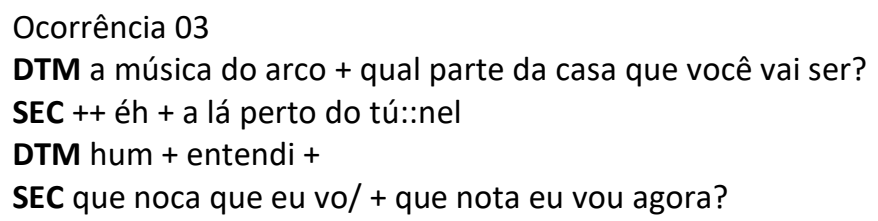

Portanto, a marca hesitativa que precede a enunciação de o que dizer no enunciado em destaque na Ocorrência 02 mostra que não se trata apenas, ou essencialmente, de se enunciar uma referência. Especialmente porque, sob a ilusão da unidade aparente do eu que se mostra no enunciado, a pausa silenciosa marca a cisão desse eu, a dispersão de sua constituição. Essa pausa pode ser interpretada, portanto, como marca de um conflito: de que 
lugar discursivo ${ }^{8}$ eu me introduzo como eu em minha própria fala? De uma multiplicidade de lugares possíveis que constituem esse eu como sujeito, um deles parece se destacar no enunciado em questão: o de um aluno (já que se trata de contexto escolar) sob avaliação.

Mas é DJZ, implantada nesse enunciado como alocutário, o alocutário discursivo desse enunciado? Assim como ocorre com a figura do eu, a pausa silenciosa do enunciado pode, também, remeter à complexidade da constituição de quem é implantado pelo eu como (seu) alocutário; basta considerar os fatos de suas condições de produção. Indícios da complexidade dessa implantação podem ser detectados no terceiro enunciado de SVV no fragmento em análise: acho que o professor L. não vai gostar. Ou seja, embora, empiricamente, DJZ seja implantada como tu nos enunciados de S02, também o professor L., discursivamente, é um tu implantado em seus enunciados. Nessa interpretação, embora construído enunciativamente como não-pessoa no enunciado de SVV, discursivamente é não apenas um alocutário, mas, talvez, seu alocutário preferencial. Assim também, pode ter sido implantado como tu (de modo não mostrado linguisticamente no enunciado) todo o contexto da oficina pedagógica que, de maneira ampla, recobre toda essa e as demais cenas enunciativas.

Decorre dessas possibilidades uma situação ainda mais complexa: de uma perspectiva discursiva, seria de autorreferência (FLORES, 2019) ${ }^{9}$ que se trata no enunciado em análise, ou essa unidade aparente sob a forma do eu mascararia a complexidade de vozes ${ }^{10}$ do alocutário que nela fala? Em outras palavras, que vozes ecoam na voz autorreferenciada como a do eu nesse enunciado?

Vimos, portanto, marcada por uma pausa silenciosa, a complexidade enunciativa subjacente à constituição de uma alocução.

E a referência? Também sua constituição complexa pode ser inferida nessa alocução. Relembre-se que a pausa silenciosa em destaque precede "não sei o que falar". Em princípio, pode-se pensar que não saber o que falar mostra o conflito entre o que dizer (dentre múltiplas possibilidades de dizeres, inclusive o próprio negar-se a dizer) na cena enunciativa a respeito do que ocorreu na situação interrogada. Nesse sentido, "não sei o que falar" emerge na cadeia em competição com "não sei escolher o que falar, dentre várias coisas que eu teria a dizer ou a silenciar". A negação de um saber expõe, portanto, o conflito do sujeito em determinado ponto do fio do discurso: "[...] colocar o 'dito' e em consequência rejeitar o 'não-dito'”; ou

\footnotetext{
${ }^{8}$ A expressão lugar discursivo remete, em nossa reflexão, ao fato de que "[...] o que funciona nos processos discursivos é uma série de formações imaginárias que designam o lugar que A e B se atribuem cada um a si e ao outro, a imagem que eles se fazem de seu próprio lugar e do lugar do outro." (PÊCHEUX, 1990, p. 82 - destaques do autor).

${ }^{9}$ Para Flores, a sui-referência ou, ainda, a sui-reflexidade em Benveniste introduz "[...] sub-repticiamente [...] a questão da autorreferência (FLORES, 2019, p. 73). Isso porque “As pessoas 'eu' e 'tu' são autorreferenciais, não comportam referência objetiva, referem a si mesmas [...]” (FLORES, 2019, p. 70 - destaque nosso).

${ }^{10}$ A ideia de vozes recupera a sustentação do pensamento de Authier-Revuz (que, de modo particular, orienta nossa reflexão) no dialogismo bakhtiniano: “O ‘dialogismo' do círculo de Bakhtin [...] não tem como preocupação central o diálogo face a face, mas constitui [...] uma teoria da dialogização interna do discurso. As palavras são, sempre e inevitavelmente, 'as palavras dos outros' [...]." (AUTHIER-REVUZ, 1990, p. 26 - destaque da autora).
} 
seja, "[...] colocar fronteiras entre o que é 'selecionado' e tornado preciso aos poucos [...] e o que é rejeitado." (PÊCHEUX; FUCHS, 1990, p. 176).

Poder-se-ia, também, pensar que o que falar teria escapado à figura que se introduz como eu em sua fala. Um esquecimento? Um desconhecimento do que the foi perguntado? Um problema momentâneo de (sua) memória? Não parece ser o caso, a julgar pela continuidade da cena enunciativa:

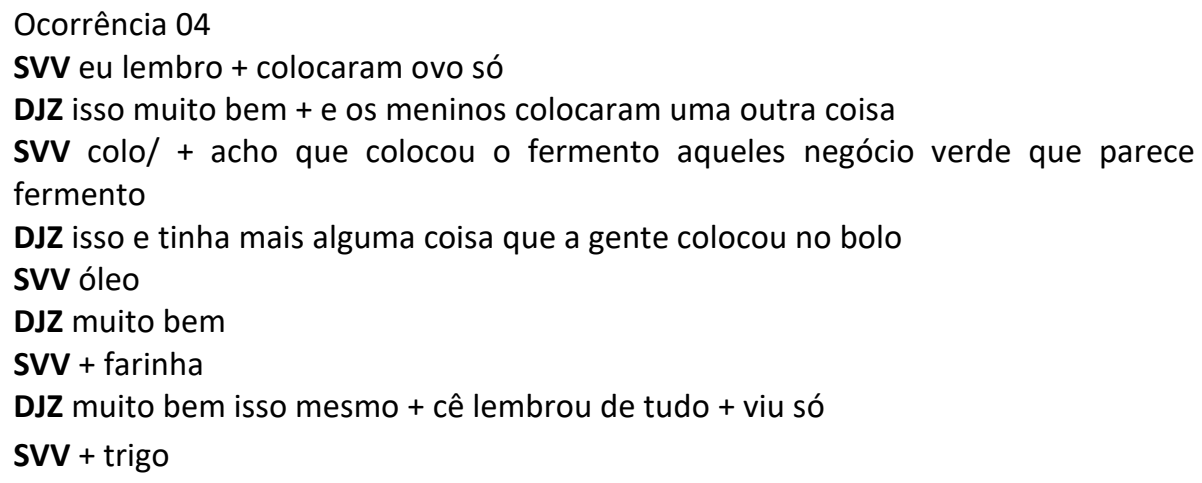

Mas, se levarmos em conta os fatos das condições de produção aos quais nos referimos anteriormente, a pausa silenciosa que antecede num sei o que falar antecipa a tensão de se enunciar não exatamente uma referência, mas a de enunciá-la conforme uma expectativa que, discursivamente, se projeta (e que se assume) como resposta. Trata-se, pois, de corresponder a uma expectativa, e não a qualquer uma: a de se ver construído como enunciador em situação de avaliação institucional, representada, direta e indiretamente, pela documentadora, pelo coordenador de um projeto, pela equipe pedagógica de uma escola, dentre outras instâncias possíveis.

Vê-se, em síntese, como, ao mostrar a complexidade enunciativa, as hesitações atualizam, no fio do discurso, conflitos que advêm da ordem do discurso.

No entanto, como ficou dito, não só fatos das condições de produção do discurso se deixam ver por meio das marcas de hesitação. Também fatos do funcionamento da língua poderiam se deixar entrever por elas. Mostramos, há pouco, de que modo a ordem da língua poderia estar na base desses conflitos, ao analisarmos a emergência das marcas hesitativas mostradas na Ocorrência 01.

Gostaríamos, no entanto, de trazer à luz mais uma situação de hesitação, na qual a ordem da língua privilegiadamente se mostra:

Ocorrência 05

SEC aco/ + o que que aconteceu? + acon/ + aconq/ o que que aconteceu vou contar + o ra/ o rato do campo e o rato da cidade correram + e + e o gato foi atrás

Dessa ocorrência, o destaque que faremos é aos três primeiros momentos hesitativos, respectivamente marcados por: (i) corte brusco e pausa silenciosa ( $a c 0 /+$ ); (ii) corte brusco e pausa silenciosa (acon/ + ); (iii) corte brusco (aconq/). Nesses três momentos, é a própria 
configuração dos significantes que parece estar em questão na emergência das hesitações. Comecemos pela palavra "aconteceu". É um quadrissílabo, ou seja, uma palavra longa (a se considerar o léxico infantil). Em sua configuração rítmica, quando falada, observam-se dois pés iambos em sequência: "a-con" e "te-ceu", ambos com padrões complexos em suas sílabas fortes ("con" e "ceu"). Essa palavra é combinada, no fio do discurso, à sequência "o que que". Além da repetição silábica (que que) que se mostra nessa sequência, há que se considerar, ainda, a sequência de oclusivas surdas não labiais na combinação entre "aconteceu" e "o que que", a saber, /t/ e /k/. Assim, é de se esperar que a combinação entre (a) extensão de palavra, (b) dois padrões rítmicos menos usuais no português brasileiro (os dois pés iambo), (c) a complexidade silábica no interior de cada um deles, (d) a repetição de sílabas (que que) e (e) movimentos articulatórios próximos de fonemas em sequência (/t/ e /k/) favoreça a emergência de hesitações. Reforça essa nossa interpretação o fato de que a própria estrutura do significante da palavra "aconteceu" se configure diferentemente, e aos poucos: "aco", "acon" e "aconq". Destaque-se, inclusive, a resolução do conflito entre /t/ e /k/ em favor de $/ \mathrm{k} /$, de modo a antecipar no resíduo "aconq" (do significante da palavra "aconteceu") a aparição do fonema /k/ da repetição que a segue ("o que que").

Como se pode observar, sendo produtos da complexidade enunciativa e, ao mesmo tempo, partes do mesmo processo, as hesitações consistem, no fio do discurso, em pontos nos quais se performatizam, além de conflitos que advêm da ordem do discurso, também conflitos que advêm da ordem da língua.

\section{Palavras (não) finais}

Com a análise que fizemos, procuramos demonstrar, primeiramente, que, ao irromperem no fio do discurso, mais do que quebrarem sua suposta continuidade, as hesitações denunciam a negociação (simulada) da figura que se introduz como eu no fio do discurso com a heterogeneidade constitutiva do (seu) discurso. É, pois, a presença do Outro que se instala nos momentos de hesitação. Nesse sentido, as hesitações poderiam, ser interpretadas como (mais uma das) formas de heterogeneidade mostrada.

Em síntese, como formas de heterogeneidade mostrada, as hesitações compõem, como produto e como parte do processo, a chamada complexidade enunciativa constituindo-se por marcas linguísticas características, como as que apontamos na análise. Dessa perspectiva, a alocução eu-tu em sua relação com a referência, por um lado, cria a ilusão da necessária unidade do deslizamento do fio do discurso. Mas, por outro lado, atua como forma de esquiva da complexa (e dispersa) constituição dessa unidade. Nem sempre com sucesso, como procuramos demonstrar, já que as hesitações, exemplarmente, deixam entrever essa complexidade.

$\mathrm{Na}$ análise, alguns aspectos dessa complexidade foram destacados. Em um primeiro momento, enfatizamos aqueles que dizem respeito à constituição dos lugares enunciativos, recuperada pela remissão a fatos das condições que os tornaram possíveis na enunciação. Em 
outras palavras, a complexidade que se pode detectar nessa constituição provém da ordem do discurso, da rede discursiva que sustenta (como um Outro) o discurso.

Mas esse Outro pode ser ainda de outra natureza, a qual se deixa ver quando observamos sua ação em momentos de hesitação. Trata-se não da "exterioridade radical" de todo discurso, mas da própria complexidade linguística. Em outras palavras, em muitos desses momentos, é da ordem da língua a complexidade que se faz mostrar sobre e pela figura do eu que enuncia.

\section{Referências}

AMERICAN SPEECH-LANGUAGE-HEARING ASSOCIATION (ASHA). Special Interest Division 4 (SID 4) - Terminology pertaining to fluency and fluency disorders: Guidelines. ASHA, v. 41, n. 19, p. 29-36, 1999.

AUTHIER-REVUZ, J. Heterogeneidade(s) enunciativa(s). Caderno de Estudos Linguísticos, Campinas, v. 19, p. 25-42, 1990.

AZEVEDO, N. P. G.; LUCENA, J. A. Perspectiva linguístico-discursiva na terapêutica da gagueira. Caderno de Estudos Linguísticos, v. 51, n. 2, p. 167-186, 2009.

https://doi.org/10.20396/cel.v51i2.8637210

BENVENISTE, É. Problemas de linguística geral II. Campinas: Pontes, 1989.

BOEYA, R. A.; WUYTSB, F. L.; HEYNINGB, P. H. V.; BODTB, M. S.; HEYLENB, L. Characteristics of stuttering-like disfluencies in Dutch-speaking children. Journal of Fluency Disorders, v. 32, p. 310-329, 2007. https://doi.org/10.1016/i.jfludis.2007.07.003

CARLO, E. J., WATSON, J. B. Disfluencies of 3- and 5-year old Spanish-speaking children. Journal of Fluency Disorders, v. 28, p. 37-53, 2003. https://doi.org/10.1016/S0094-730X(03)00004-4

CARNEIRO, C. R. Refletindo sobre a gagueira de um ponto de vista linguístico. Caderno de Estudos Linguísticos, v. 35, p. 448-453, 2006.

CHACON, L.; CAMILLO, M. Questões de linguagem na doença de Parkinson: as hesitações. São Paulo: Cultura Acadêmica, Editora UNESP, 2014.

CHACON, L.; VILLEGA, C. C. S. Hesitações na fala infantil: indícios da complexidade da língua. Caderno de Estudos Linguísticos, Campinas, v. 54, n. 1, p. 81-95, 2012.

https://doi.org/10.20396/cel.v54i1.8636973

CHACON, L.; VILLEGA, C. C. S. Language acquisition: hesitations in the question/answer dialogic pair. CoDAS, v. 27, p. 73-79, 2015. https://doi.org/10.1590/2317-1782/20152014048

DE LEMOS, C. T. G. Das vicissitudes da fala da criança e de sua investigação. Caderno de Estudos Linguísticos, Campinas, v. 42, n. 1, p. 41-69, 2002.

https://doi.org/10.20396/cel.v42i0.8637140

FLORES, V. N. Problemas gerais de linguística. Petrópolis: Vozes, 2019.

JAKOBSON, R. Linguística e comunicação. 20. ed. São Paulo: Cultrix, 1995. 
JUSTE, F.; ANDRADE, C. R. F. Tipologia das rupturas de fala e classes gramaticais em crianças gagas e fluentes. Pró-Fono Revista de Atualização Científica, v. 18, n. 2, p. 129-140, 2006. https://doi.org/10.1590/S0104-56872006000200002

MARCUSCHI, L. A. A hesitação. In: NEVES, M. H. M. Gramática do português falado: novos estudos. Campinas: UNICAMP/FAPESP, 1999. p. 159-194.

MARCUSCHI, L. A. Fenômenos intrínsecos da oralidade: a hesitação. In: KOCH, I. G. V.; JUBRAN, C. C. A. S. Gramática do português falado: construção do texto falado. Campinas: Editora da Unicamp, 2006. p. 48-70.

MARTINS V. O.; ANDRADE, C. R. F. Perfil evolutivo da fluência da fala de falantes do português brasileiro. Pró-Fono Revista de Atualização Científica, v. 20, n. 1, p. 7-12, 2008. https://doi.org/10.1590/S0104-56872008000100002

MELO, C. G.; CHACON, L. Relações entre pausas e constituintes prosódicos na fala de crianças com desenvolvimento típico de linguagem. Audiol Commun Res., v. 20, n. 1, p. 18-23, 2015. https://doi.org/10.1590/S2317-64312015000100001410

NASCIMENTO, J. C. Fenômeno hesitativo na linguagem: um olhar para a doença de Parkinson. 2005, 158 f. Dissertação (Mestrado em Estudos Linguísticos) - Programa de Pós-Graduação em Estudos Linguísticos, Universidade Estadual Paulista "Júlio de Mesquita Filho", São José do Rio Preto, 2005.

NATKE, U.; SANDRIESER, P.; PIETROWSKY, R.; KALVERAM, K. T. Disfluency data of German preschool children who stutter and comparison children. Journal of Fluency Disorders, v. 31, p. 165-176, 2006.

NESPOR, M; VOGEL, I. Prosodic phonology. Dordrechet: Foris Publications, 1986.

PÊCHEUX, M. Análise automática do discurso. In: GADET, F; HAK, T. (Orgs.) Por uma análise automática do discurso: uma introdução à obra de Michel Pêcheux. Campinas: Editora da UNICAMP, 2000. p. 61-161.

PÊCHEUX, M.; FUCHS, C. A propósito da análise automática do discurso: atualização e perspectivas. In: GADET, F; HAK, T. (Orgs.) Por uma análise automática do discurso: uma introdução à obra de Michel Pêcheux. Campinas: Editora da UNICAMP, 2000. p. 163-252.

RAMOS, S. Hesitações e rupturas na fala infantil: as franjas da teoria e o lugar do sujeito na aquisição. 2008, 102 f. Dissertação (Mestrado em Linguística) - Programa de Pós-Graduação em Linguística, Universidade Estadual de Campinas, Campinas, 2008.

RAMOS, S.; SCARPA, E. M. Hesitações e rupturas em aquisição da linguagem: os processos reorganizacionais na fala infantil. Caderno de Estudos Linguísticos, Campinas, v. 36, n. 2, p. 348-354, 2007.

SCARPA, E. M. Sobre o sujeito fluente. Caderno de Estudos Linguísticos, v. 29, p. 163-184, 1995.

SCARPA, E. M. Disfluências e estrutura prosódica na fala adulta e infantil. Revista Pro língua, v. 10, n. 1, 2015.

VIEIRA, R. C. R.; CHACON, L. Movimentos da hesitação: deslizamentos do dizer em sujeitos com doença de Parkinson. São Paulo: Cultura Acadêmica, Editora UNESP, 2015. https://doi.org/10.7476/9788579836640 
WATSON, J. B.; ANDERSON, R. T. Disfluencies of 2- and 3-Year-Old Spanish-Speaking Children From Puerto Rico. Contemporary Issues In Communication Science and Disorders, v. 28, p. 140-150, 2001.

Recebido em: 03/12/2019.

Aceito em: 09/03/2020. 